\title{
N.D. Dvurechenskaja, A.N. Gorin, K.A. Shejko. \\ « МОНЕТЫ ИЗ КРЕПОСТИ УЗУНДАРА (ПО РЕЗУЛЬТАТАМ РАБОТ 2013-2014 ГГ.) »
}

Johanna Lhuillier

\section{(2) OpenEdition}

\section{Journals}

\section{Édition électronique}

URL : http://journals.openedition.org/abstractairanica/44659

DOI : 10.4000/abstractairanica.44659

ISBN : 1961-960X

ISSN : 1961-960X

Éditeur :

CNRS (UMR 7528 Mondes iraniens et indiens), Éditions de l'IFRI

Référence électronique

Johanna Lhuillier, « N.D. Dvurechenskaja, A.N. Gorin, K.A. Shejko. « Монеты из крепости Узундара (по результатам работ 2013-2014 гг.) » », Abstracta Iranica [En ligne], Volume 37-38-39 | 2018, document 3, mis en ligne le 30 décembre 2018, consulté le 28 septembre 2020. URL : http:// journals.openedition.org/abstractairanica/44659; DOI : https://doi.org/10.4000/abstractairanica. 44659

Ce document a été généré automatiquement le 28 septembre 2020.

Tous droits réservés 


\title{
N.D. Dvurechenskaja, A.N. Gorin,
} K.A. Shejko. « МОНЕТЫ Из КРЕПОСТИ УЗУНДАРА (ПО РЕЗУЛЬТАТАМ РАБОТ 20132014 ГГ.) »

\author{
Johanna Lhuillier
}

\section{RÉFÉRENCE}

N.D. Dvurechenskaja, A.N. Gorin, K.A. Shejko. « МОНЕТЫ ИЗ КРЕПоСТИ УЗУНДАРА (ПО РЕЗУЛЬТАТАМ РАБОТ 2013-2014 Гг.) » [« Monety iz kreposti Uzundara (po rezul'tatam rabot 2013-2014 gg.) »: Coins From The Fortress Uzundara (As Based On The Results of The Works In 2013-2014)], Scripta Antiqua, Ancient History, Philology, Arts and Material Culture 5, Moscou, 2016, p. 347-366.

1 Cet article livre une présentation détaillée de 23 monnaies mises au jour dans la forteresse hellénistique d'Uzundara, dans le nord de la Bactriane ouzbèke, lors de trois campagnes de terrain menées entre 2013 et 2014. Ces monnaies, qui proviennent majoritairement de la surface du site, comprennent 1 monnaie séleucide, 15 monnaies gréco-bactriennes, 4 imitations de monnaies d'Hélioclès et 3 monnaies kouchanes de Sôter Mégas. On peut regretter qu'elles ne soient pas illustrées mais un long tableau permet d'embrasser du regard les principales informations (description de l'avers et du revers, poids, dimensions, contexte de découverte). 


\section{AUTEURS}

JOHANNA LHUILLIER

UMR 5133 CNRS-Université de Lyon 